\title{
Testing 'Proportion of Females Calving' as an indicator for population-level reproductive performance for black rhinoceros (Diceros bicornis)
}

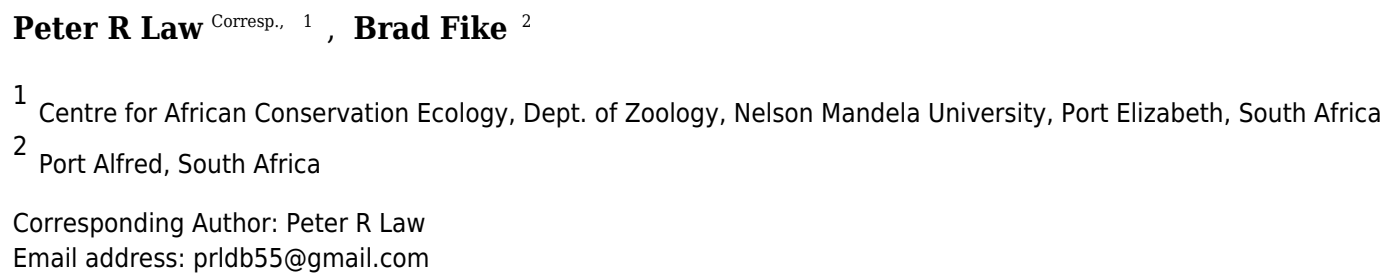

The proportion of females calving (PFC) each year has been employed as an indicator of population reproductive performance in ungulates, especially for species that breed annually, because it requires less detailed population data than inter-birthing intervals and age at first reproduction. For asynchronous breeders with inter-birthing intervals longer than a year such as megaherbivores, however, it is unclear how much annual variation in PFC is expected and whether false signals of density feedback or environmental influence might result from analyzing PFC data. We used census data from a well studied, closed, expanding population of black rhinoceros (Diceros bicornis) to study annual variation in PFC over 22 years. Our analysis of PFC data yielded no false signals of density feedback but weak evidence for an unexpected influence of rainfall. The PFC data exhibited considerable variation, which we attribute to autocorrelation in the time series of PFC data, 'demographic-founding effects', changes in stage structure, and demographic stochasticity, some of which modelling of PFC appears to confuse with an influence of rainfall. We expect such variation to be common in introduced populations and to persist for some years, complicating the interpretation of PFC, though moving averages of PFC can help if employed cautiously. While our analysis does not undermine the possible utility of PFC, the analysis and interpretation of PFC values requires care. 
1 Testing 'Proportion of Females Calving' as an indicator for population-level reproductive

2 performance for black rhinoceros (Diceros bicornis).

3

4 Peter R Law ${ }^{1}$, Brad Fike ${ }^{2}$

$5{ }^{1}$ Centre for African Conservation Ecology, Department of Zoology, Nelson Mandela University,

6 P. O. Box 7700, Port Elizabeth, 6031, Republic of South Africa. prldb55@gmail.com

7 2 P.O. Box 4038, Port Alfred 6170, Republic of South Africa. bradfike80@gmail.com

8 Corresponding author: Peter R Law

9 Email: prldb55@gmail.com

12 Running Title: Proportion of females calving

\section{Abstract}

14 The proportion of females calving (PFC) each year has been employed as an indicator of 15 population reproductive performance in ungulates, especially for species that breed annually, because it requires fewer detailed population data than inter-birthing intervals and age at first reproduction. For asynchronous breeders with inter-birthing intervals longer than a year such as megaherbivores, however, it is unclear how much annual variation in PFC is expected and whether false signals of density feedback or environmental influence might result from analyzing PFC data. We used census data from a well studied, closed, expanding population of black rhinoceros (Diceros bicornis) to study annual variation in PFC over 22 years. Our analysis of PFC data yielded no false signals of density feedback but weak evidence for an unexpected influence of rainfall. The PFC data exhibited considerable variation, which we attribute to autocorrelation in the time series of PFC data, 'demographic-founding effects', changes in stage structure, and demographic stochasticity, some of which modelling of PFC appears to confuse with an influence of rainfall. We expect such variation to be common in introduced populations and to persist for some years, complicating the interpretation of PFC, though moving averages of 
28 PFC can help if employed cautiously. While our analysis does not undermine the possible utility 29 of PFC, the analysis and interpretation of PFC values requires care.

\section{Introduction}

32 Studying megaherbivore population dynamics is challenging due to the longevity of individuals.

33 The resources required to identify and monitor individuals over long periods of time may be costly, involving technological challenges and long-term commitments from dedicated personnel, while the populations themselves are open to unnatural disturbances (poaching). Both intrinsic ecological interest and conservation demands, especially for rhinoceros (IUCN red list: Ceratotherium simum near threatened, Rhinoceros unicornis vulnerable, and Diceros bicornis, Dicerorhinus sumatrensis and Rhinoceros sondaicus all critically endangered), nevertheless make such studies important. In the absence of demographic histories of individuals, practical measures that might reflect population performance could be valuable.

41 For ungulates species with synchronized annual breeding, the proportion of adult females calving (hereafter PFC) each breeding season provides a measure of population reproductive performance (Fryxell 1987). Imperfect detection can undermine the reliability of counts estimating PFC (Bonenfant, Gaillard, Klein \& Hamann 2005), but that is not our concern here. Rather, we focus on the interpretation and utility of PFC, when accurately estimated, for megaherbivores that are asynchronized, non-seasonal breeders with inter-birthing intervals longer than a year. Observation must occur over the entire year due to the lack of a birthing season and only a fraction of mature females will be available to breed in any given year, inducing autocorrelations in a time series of PFC data. Moreover, annual variation in PFC may not reflect drivers of population performance, such as density feedback and environmental influence. Instead, annual fluctuations in PFC may be more sensitive to demographic stochasticity and 'demographic-founding effects', i.e., demographic consequences of the distribution of sex and (st)age amongst the introduced individuals founding reintroduced populations, especially as many extant populations of rhinoceros, in particular, are small and recently reintroduced. Nevertheless, one of du Toit's (2001) benchmarks of black rhinoceros population performance in the wild is ' $\%$ of cows with calf of that year' $(<29 \%$, very poor - 
57 poor; $29-33 \%$, poor - mod; $33-40 \% \bmod -$ good; $>40 \%$ good - excellent). PFC has also been

58 exploited in demographic studies of black rhinoceros populations (Hrabar and du Toit 2005,

59 Okita-Ouma 2014).

60 Our aim in this paper is to investigate the performance of PFC as a measure of population-

61 level reproductive performance by analyzing PFC for a population of black rhinoceros (Diceros

62 bicornis minor) for which complete individual histories were known (Fike 2011). Previous study

63 of the demography of this population based on the complete individual histories (Law, Fike and

64 Lent 2013, 2104, 2015) permitted us to frame expectations of PFC if it is to provide a reliable

65 measure of population-level reproductive performance and to test those expectations. We studied

66 mortality, age at first reproduction, and inter-birthing intervals in Law et al. (2013), and birth sex

67 in Law et al. (2014). Through modelling, the only evidence of density feedback we found on

68 these demographic parameters was increasing age at first reproduction with increasing

69 population size. We found no evidence for an influence of: total rainfall over 15 (or 24) months

prior to the first birth on age at first reproduction; total rainfall during an inter-birthing interval or the six months prior to the beginning of an inter-birthing interval on the inter-birthing interval; total rainfall during gestation or total rainfall during the periods of 7, 12, or 24 months prior to conception on birth sex. Neither maternal identity nor age, nor the sex of the calf that initiated an inter-birthing interval, explained variation in inter-birthing intervals, while variation in birth sex was not accounted for by maternal identity or age, year of conception, or population adult sex ratio. Yet variation in inter-birthing intervals and birth sex persisted throughout the 22 years of the study. On the basis of these results, we conjectured that variation was due, at least in part, to demographic stochasticity. In Law et al. (2015), we fitted semi-annual population census counts to various models of population dynamics expected to be suitable for megaherbivores (OwenSmith 2010). A model of exponential growth with intrinsic annual rate of growth estimated as $0.102 \pm 0.017$ was unambiguously the best model fit to the data. Using this scalar exponential model and the method of Lande et al. (2003:19 - 20) (see also Morris and Doak 2002:127 - 128) and also a more detailed stage-based matrix model of the population with the method of Engen et al. (2005), we obtained estimates of demographic stochasticity that supported our earlier contention of a role for demographic stochasticity in explaining variation in birth numbers and sexes throughout the study period. 
87 Our previous results enabled us to interpret the population-level PFC values and assess their 88 utility. In particular, we found only a subtle signal of density feedback on our study population 89 and no signal of environmental influence, so we can test whether analyses of PFC data can

90 falsely suggest either influence. During the phase of exponential growth, which is expected to be 91 prolonged for a population of megaherbivores (McCullough 1992), annual variation in PFC 92 values can reflect demographic stochasticity and demographic-founding effects as life stages 93 move towards stable distribution. By quantifying this variation for our study population, we 94 provide a measure of the background variation against which responses to density feedback and 95 environmental influence, if present, need stand out. For our study population, the mean interbirthing interval was $29.0 \pm 0.9$ months, $(n=77)$, so one might expect about $1 / 2.5=0.4$ of

97 already adult females to calve each year in an exponentially growing population in good habitat, 98 not accounting for instances of first calving during the year. We predict variation in PFC about 0.4 for our study population. We also examined moving averages of PFC values.

We expect there will be fluctuations in PFC due to autocorrelations and stochasticity, especially during phases of growth at small population size. Our previous studies have shown that population density and rainfall do not explain variation in individual-level indicators of demography such as inter-birthing intervals, age at first reproduction, and birth sex. We therefore hypothesize that if PFC is a reliable measure of population-level reproductive, analyses of our PFC data with covariates of population density and rainfall will not implicate these covariates as meaningful explanations of variation in PFC. We are able to test this hypothesis with the data of our study population given our previous detailed demographic study of its individual-level demography.

\section{Materials and Methods}

111 The study site is managed by the Eastern Cape Parks and Tourism Agency (ECPTA). The

112 ECPTA is mandated by its enabling act to monitor black rhinoceros under its care and to conduct

113 research in aid of their management (pers. comm., Dean Peinke, ECPTA). Treatment of

114 individual black rhinoceros for the purposes of management and monitoring employs

115 professional practices, by qualified personnel, based on decades of experience (e.g., Morkel and 
116 Kennedy-Benson 2007). In particular, the individuals of the study population were ear notched to

117 meet the mandated monitoring goals, in a responsible manner reflecting both the ethical

118 treatment of animals (Sikes et al. 2011) and the high value of individuals of this critically

119 endangered species. Monitoring itself was conducted by aerial surveys using a microlight

120 aircraft, observations by ground patrols, and camera traps. These procedures were conducted so

121 as to minimally interfere with the subjects. Our research merely took advantage of the data

122 accumulated by this monitoring. Field work was therefore not a part of this study and no permits

123 were required.

124 The study population was a closed population 1986 - 2008, apart from several introductions

125 (totaling 23 individuals that survived introduction), which ceased at the end of 1997, and the

126 removal of five subadults in 2006, the latter having negligible effect on demography prior to

127 2009. Introduced into a well defined area of $220 \mathrm{~km}^{2}$ within the Great Fish River Reserve in the

128 Eastern Cape, South Africa, the population grew monotonically from an initial release of four

129 animals to 110 individuals by the end of 2008 (see Figure 1 and Table 1) with the number of

130 female adults increasing monotonically from 1 to 29 . The study site is considered excellent black

131 rhinoceros habitat (van Lieverloo et al. 2009, Fike 2011). Further details may be found in Fike

132 (2011) and Law et al. (2013, 2014, 2105). All rhinoceroses were individually identifiable and we

133 possessed complete individual histories 1986 - 2008 from which we computed exact PFC values

1341987 - 2008 as follows. We employed the stage-based definition of 'adult' female of Law and

135 Linklater (2014), reflecting the biology and life history of the species, used throughout our

136 studies: a female is adult if she has calved or reached the age of seven years without calving. For

137 a given year, we counted any individual that was alive as an adult female during part of that year.

138 PFC was then the number of births during the year divided by that count.

139 We first applied the standard arcsine-square-root transformation to PFC as is customary for

140 proportions. We also calculated a modified version that better normalizes proportions close to

141 zero and one (Zar 1999, equation 13.8), see Figure 2. As the results did not depend qualitatively

142 on the choice of transformation, we only report results for the modified transformation, which we

143 denote transPFC. As covariates we employed: population density at the beginning of the year for

144 which PFC was computed (hereafter 'density'); a lagged version of density, computed 12 months

145 prior to that just defined, was highly correlated with density $(0.99$, reflecting the monotonic 
146 growth in population size) and was discarded as uninformative; total rainfall for the calendar

147 year for which PFC was computed ('rain'); and total rainfall for the prior year ('rain1'). The two

148 rain measures were only negligibly correlated (-0.06). The predictors were mean centred and

149 standardized by dividing by their standard deviations.

150 Given that our data form a time series in which we expect autocorrelations and for which we

151 also need to examine the possible influence of covariates, autoregressive (AR) modelling

152 provides a suitable approach to analyzing our data. AR modelling has the further advantage of

153 being based on maximum likelihood methods, which permits the use of the Akaike information-

154 criterion method of model ranking and selection, which has many advantages over null

155 hypothesis testing (Burnham and Anderson 2002). We first examined (partial) autocorrelations to

156 determine the order of the AR model and also the window for constructing moving averages of

157 the raw data. We constructed AR models using the R package MARSS (Holmes et al. 2014) with

158 transPFC as response. We used the second-order correction $\mathrm{AIC}_{\mathrm{c}}$ (Burnham and Anderson 2002)

159 to rank all $2^{5}=32$ models with different combinations of covariates. We performed model

160 averaging over the models in this ranking whose Akaike weights summed to 0.95 and also

161 computed the relative importance of the covariates, i.e., the sum of Akaike weights over the

162 models in which a variable appears (Burnham and Anderson 2002).

163

164 Results

165 From Figure 3, autocorrelations do not suggest any cyclic behaviour in the time series. The most

166 important partial autocorrelations were for lag one and lag two so we chose our global

167 autoregressive model to be $\mathrm{AR}(2)$. With transPFC $\mathrm{P}_{\mathrm{i}}$ denoting the value of transPFC $i$ years prior

168 to the response, our global model was:

$169 \operatorname{transPFC}=\mathrm{b}_{0}+\mathrm{b}_{1} \operatorname{trans} \mathrm{PFC}_{1}+\mathrm{b}_{2} \operatorname{trans} \mathrm{PFC}_{2}+\mathrm{c}_{1}$ density $+\mathrm{c}_{2}$ rain $+\mathrm{c}_{3} \operatorname{rain}_{2}+\varepsilon$

170 with $\varepsilon \sim \mathrm{N}\left(0, \sigma^{2}\right)$. The global model explained $46 \%$ of the variance in the response variable, a

171 respectable amount for an ecological model per Møller and Jennions (2002).

172 The relative importances of the variables were: 0.9353 , $\operatorname{trans} \mathrm{PFC}_{1} ; 0.4971, \operatorname{trans} \mathrm{PFC}_{2} ; 0.2807$, 173 rain; 0.1609 , rain $1 ; 0.1531$, density. The top 14 models, accounting for $95 \%$ of cumulative 
174 Akaike weights, appear in Table 2. The model average (Burnham and Anderson 2002:152), over

175 these 14 models, of the coefficients and SEs of transPFC ${ }_{1}, \operatorname{trans} \mathrm{PFC}_{2}$ and rain were $-0.55 \pm 0.21$,

$176-0.16 \pm 0.20$, and $-0.012 \pm 0.021$, respectively.

177 The mean PFC $\pm \mathrm{SD}$ was $0.40 \pm 0.24$. For 3-11-year moving averages, the means were 0.40

178 with SEs decreasing monotonically from 0.063 to 0.016 with the window size of the moving

179 average. Since the larger the window over which one computes a moving average the fewer

180 moving averages result, we chose the smallest window that reflected the (partial)

181 autocorrelations and the AR modelling results. Figure 3 together with the dominance of the first

182 lag in the AR modelling suggested that a three-year moving average of PFC values would suffice

183 for our data, employment of which did not alter the mean but reduced the SE to only $26 \%$ that of

184 the raw data.

\section{Discussion}

186 For our study population, AR-modelling demonstrated negative correlations between PFC and

187 its values in the previous two years, that with the previous year's being the stronger, consistent

188 with Figure 3 and the mean length of inter-birthing intervals of 29 months. With a gestation of 15

189 months, a female that calved this year is extremely unlikely to have calved last year, and on

190 average not the year before that either. Thus, the AR-modelling revealed the expected

191 autocorrelation in the time series of PFC data. Total rainfall during the year in which PFC was

192 measured was the most important of the three covariates but its relative importance was only

$19356 \%$ that of PFC lagged by two years and only 30\% of that of PFC lagged by one year. Its

194 regression coefficient is negative as is the correlation between the rain and PFC values $(-0.186)$,

195 counterintuitive to expectations of how rainfall might influence PFC. Density was the least

196 important covariate. Since our detailed study of demography (Law et al. 2013, 2014) detected no

197 influence of relevant measures of rainfall on vital rates and birth sex and only density feedback

198 on age at first reproduction, we conclude that for our study population the AR-modelling

199 provided no false signal of density feedback but weak evidence of an influence of rainfall that is

200 not supported by our more detailed prior studies (Law et al. 2013, 2014). The success of AR-

201 modelling in rejecting density as an influential covariate, no doubt reflects the fact that density

202 increased monotonically during the study while no correlated trend in PFC values is apparent. As

203 one would expect on statistical grounds, AR-modelling may, however, be misled to attribute 
204 variation in a time series of PFC values to a covariate (here rain) that exhibits some correlation

205 with the PFC values even if it is not in fact driving that variation. Thus, our hypothesis is not

206 unambiguously confirmed. Rather, when AR-modelling indicates the influence of a covariate on

207 PFC values, independent evidence for an influence of that covariate on vital rates should be

208 sought for confirmation. Such will also provide deeper insight into the dynamics of the

209 population.

210 Discounting the covariates in the AR-modelling, the explained variation, manifested in the

211 lagged versions of transPFC, can therefore be understood as due to the contingencies of

212 breeding, including demographic-founding effects, in combination with inter-birthing intervals

213 longer than a year, consistent with expectations. The global model left unexplained 54\% of

214 variation in transPFC, however. The unexplained variation left in age at first reproduction and

215 inter-birthing intervals in Law et al. (2013) and birth sex in Law et al. (2014), was traced to the

216 variation in birth numbers and sexes unexplained by the demographic models in Law et al.

217 (2015) and linked there to demographic stochasticity. We therefore propose that the variation in

218 PFC unexplained by the AR modelling here also reflects demographic stochasticity.

219 PFC would appear not to be sensitive enough to detect the subtle signal of density feedback our 220 individual-level demographic study detected; namely, an increase of age at first reproduction but

221 no influence on inter-birthing intervals, birth sex, or population growth rate. This finding is

222 similar to density feedback on conception rate in a population of white-tailed deer (Odocoileus

223 virginianus borealis) despite none on population growth rate (McCullough 1979:155) and

224 consistent with expectations that density will impact juvenile/subadult fecundity (i.e., age at first

225 reproduction) before impacting adult fecundity or survival in large ungulates, especially

226 megaherbivores (Eberhardt 2002). Detecting increasing age at first reproduction could warn of

227 impending density feedback on population growth rate itself and therefore would be more useful

228 than tracking PFC as a detector of density, even if more demanding of data collection. Indeed, if

229 the per capita rate of population growth rate is ramp-like (i.e., exponential growth followed by a

230 rapid decline to zero, McCullough 1992, Owen-Smith 2010) and Eberhardt's schedule for the

231 impact of density on vital rates is correct, one might expect PFC to be largely insensitive to

232 density during much of the growth phase of a population of megaherbivores. But only further

233 study of suitable populations can inform this issue. Indeed, the impact of density on 
234 megaherbivore population dynamics and vital rates remains an important gap in our knowledge,

235 due to the rarity of long-term, detailed, studies of undisturbed growing populations.

236 Setting aside the question of employing PFC to study trends in population-level reproductive

237 performance, even for a healthily expanding population such as our study population, PFC can

238 vary considerably from year to year (Fig. 2), and therefore perhaps mislead as regards population

239 reproductive performance if annual values are interpreted naively. While fluctuations in PFC will

240 not be surprising when the population is small, even in 2007, ten years after introductions had

241 ceased, PFC was only 0.26 , very poor by du Toit's benchmarks, yet 0.56 the year before and

2420.45 the year after. Even more extreme, PFC in 2000 was 0.08 , preceded by a value of 0.44 in

2431999 and followed by 0.65 in 2001 . Very high and very low PFC values are to be expected with

244 even moderately sized populations of 50 - 100, especially when demographic-founding effects

245 persist. The introduced females in our study population consisted of $71 \%$ subadults, of which

$24670 \%$ were introduced in 1997. Coincident first reproductions of introduced females were a

247 component of demographic-founding effects in our study population that contributed to high

248 PFC values in some years and low values in the succeeding year. But variation in both inter-

249 birthing intervals and birth sex continued in our study population through 2008 even as the

250 population stage structure closely approached a stable distribution. This variation was attributed

251 to demographic stochasticity in Law et al. (2015) and must be a component of the fluctuations in

252 PFC for our study population. Consistent with our analyses and expectations of no environmental

253 influence and only a subtle density feedback, there is no apparent trend in PFC values or a

254 sustained reduction to lower values at any point. There was also considerable variation about a

255 trend in PFC values detected by Hrabar and du Toit (2005; Fig. 4) and in Okita-Ouma's (2014;

256 Fig. 3.4) data for seven populations, with examples of no trend, increasing trend, and decreasing

257 trend against (delayed) density (see also Okita-Ouma Fig. 5.5 for plots of three-year moving

258 averages).

259 Moving averages can expose longer term trends by suppressing shorter term fluctuations. PFC

260 values for our study population were never consistently at least 0.4 , the threshold for du Toit's

261 benchmark for good to excellent rating. Moving averages converged on the mean PFC value

262 with increasing window size (consistent with an absence of any linear trend in the data over

263 time). For a fixed window, the overall mean was not altered but the SD decreased, by 74\% even

264 for a three-year moving average. Moving averages could be helpful in evaluating the significance 
265 of individual PFC values, e.g., when applying a rule of thumb like du Toit's to monitor

266 introduced rhinoceros populations. Partial autocorrelations in time series of PFC values might

267 also be driven by environmental stochasticity, however, and should not be simply averaged away

268 without discretion

\section{Conclusion}

270 We have presented a study, with high quality data, of accurate PFC values for a population of 271 black rhinoceros. Our aim was not to advocate for or against PFC as a useful surrogate in the 272 absence of individual-level demography but to test its performance on our study population. A 273 time series of PFC values for a population of megaherbivores can be expected to exhibit 274 autocorrelations reflecting inter-birthing intervals longer than a year thus causing fluctuations 275 and to also manifest variation arising from founding effects and demographic stochasticity at 276 population sizes not atypical for megaherbivores. AR modelling may misinterpret covariates as

277 drivers of such variation in PFC when merely correlated, though the evidence provided for such 278 a false signal by the model may be only weak. Evidence from analysis of PFC values for drivers 279 of population-level reproductive performance should therefore be supplemented by more detailed 280 study of the potential influence of a covariate on actual vital rates. PFC also appears less 281 sensitive than age at first reproduction at detecting incipient density feedback. In the absence of 282 driven fluctuations, PFC can still show considerable variation, especially for introduced 283 populations, for at least a couple of decades. During this period, moving averages of PFC may 284 reflect population-level reproductive performance better than PFC itself. Further testing of PFC 285 in other populations would be valuable, especially those exhibiting density feedback on vital 286 rates. We conclude that while PFC may be a convenient tool to attempt to measure population287 level reproductive performance, one must be careful not to over interpret its variation. For 288 megaherbivores at least, it should perhaps be regarded as a preliminary measure that can indicate 289 the direction of more intensive demographic study.

\section{Acknowledgements}

292 We thank the referees for useful suggestions that improved the manuscript and Dean Peinke at 293 the Eastern Capes Park and Tourism Agency. 


\section{References}

Bonenfant, C., Gaillard, J.-M., Klein, F. \& Hamann, J.-L. 2005. Can we use the young:female ratio to infer ungulate population dynamics? An empirical test using red deer Cervus

Burnham, K.P. \& Anderson, D.R. 2002. Model Selection and Multimodel Inference: A Practical Information-Theoretic Approach. Second Edition. New York, USA: Springer.

Du Toit, R. 2001. Benchmarks for rhino population performance in the wild. Proceedings of a SADC Rhino Management Group (RMG) Workshop in Biological Management to Meet Continental and National Black Rhino Conservation Goals. Giants Castle, South Afriuca 24-26 July, 2001 (pp 25-26).

Eberhardt, L.L. 2002. A paradigm for population analysis of long-lived vertebrates. Ecology, 83, 2841-2854.

Engen S, Lande R, Sæther B-E \& Weimerskirch H. 2005. Extinction in relation to demographic and environmental stochasticity in age-structured models. Mathematical Biosciences 195, $210-227$.

Fike, B. 2011. The Demography and Population Dynamics of a Re-Introduced Black Rhinoceros Population on the Great Fish River Reserve, Eastern Cape Province. (Unpublished M.Sc. thesis), Grahamstown, South Africa: Rhodes University.

Fryxell, J.M. 1987. Food limitation and demography of a migratory antelope, the white-eared kob. Oecologia, 72, 83-91.

Holmes, E.E., Ward, E.J. \& Scheuerell, M.D. 2014 Analysis of multivariate time series using the MARSS package, version 3.9. CRAN.R-project.org/package=MARSS population: Pilanesberg National Park, South Africa. Animal Conservation, 8, 259-267. 
319 Lande R, Engen S, Sæther B-E. 2003. Stochastic population dynamics in ecology and

320 conservation. New York, USA: Oxford UP.

321 Law, P.R., Fike, B. \& Lent, P.C. 2013. Mortality and female fecundity in an expanding black

322

323

324

325

326

327

328

329

330

331

332

333

334

335

336

337

338

339

340

341

342 rhinoceros (Diceros bicornis minor) population. European Journal of Wildlife Research, $59,477-485$.

Law, P.R., Fike, B. \& Lent, P.C. 2014). Birth sex in an expanding black rhinoceros (Diceros bicornis minor) population. Journal of Mammalogy, 95, 349-356.

Law, P.R., Fike, B. \& Lent, P.C. 2015. Dynamics of an expanding black rhinoceros (Diceros bicornis minor) population. European Journal of Wildlife Research, 61, 601-609.

Law, P.R. \& Linklater, W.L. 2014. Black rhinoceros demography should be stage, not age, based. African Journal of Ecology, 52, 571-573.

McCullough, D.R. 1979. The George Reserve Deer Herd: Population Ecology of a K-Selected Species. Ann Arbor, USA: The University of Michigan Press.

McCullough, D.R. 1992. Concepts of large herbivore population dynamics. In D.R. McCullough \& R.G. Barrett (Eds), Wildlife 2001: Populations (pp 967-984). Barking, UK: Elsevier.

Møller, A.P. \& Jennions, M.D. 2002. How much variance can be explained by ecologists and evolutionary biologists? Oecologia, 132, 492-500.

Morkel, P. \& Kennedy-Benson, A. 2007. Translocating black rhino: current techniques for capture, transport, boma care, release and post-release monitoring. Report to the African Rhino Specialist Group (85 pp.); available from www.rhinoresourcecenter.com.

Morris W.F. \& Doak D.F. 2002. Quantitative Conservation biology: Theory and Practice of Population Viability Analysis. Sunderland, MA, USA: Sinauer.

Okita-Ouma, B. 2014. Population densities of eastern black rhinoceros: Unravelling the controls. PhD Thesis. Wageningen University, the Netherland. 
343 Owen-Smith, N (ed) 2010. Dynamics of Large Herbivore Populations in Changing

Environments: Towards Appropriate Models. Chichester, UK: Wiley-Blackwell.

345 Sikes, R.S., Gannon, W.L. \& the Animal Care and Use Committee of the American Society of 346 Mammalogists. 2011. Journal of Mammalogy, 92, 235-253.

347 Van Lieverloo, R.J., Schuiling, B.F., De Boer W.F., Lent, P.C., De Jong, C.B., Brown, D. \& 348 Prins, H.H.T. 2009. A comparison of faecal analysis with backtracking to determine the diet composition and species preference of the black rhinoceros (Diceros bicornis minor). European Journal of Wildlife Research, 55, 505-515.

Zar, J.H. 1999. Biostatistical Analysis. Fourth Edition. Upper Saddle River, USA: Prentice Hall. 
Figure 1

Plot of PFC (๑) along with population size $(O)$ for the study population.

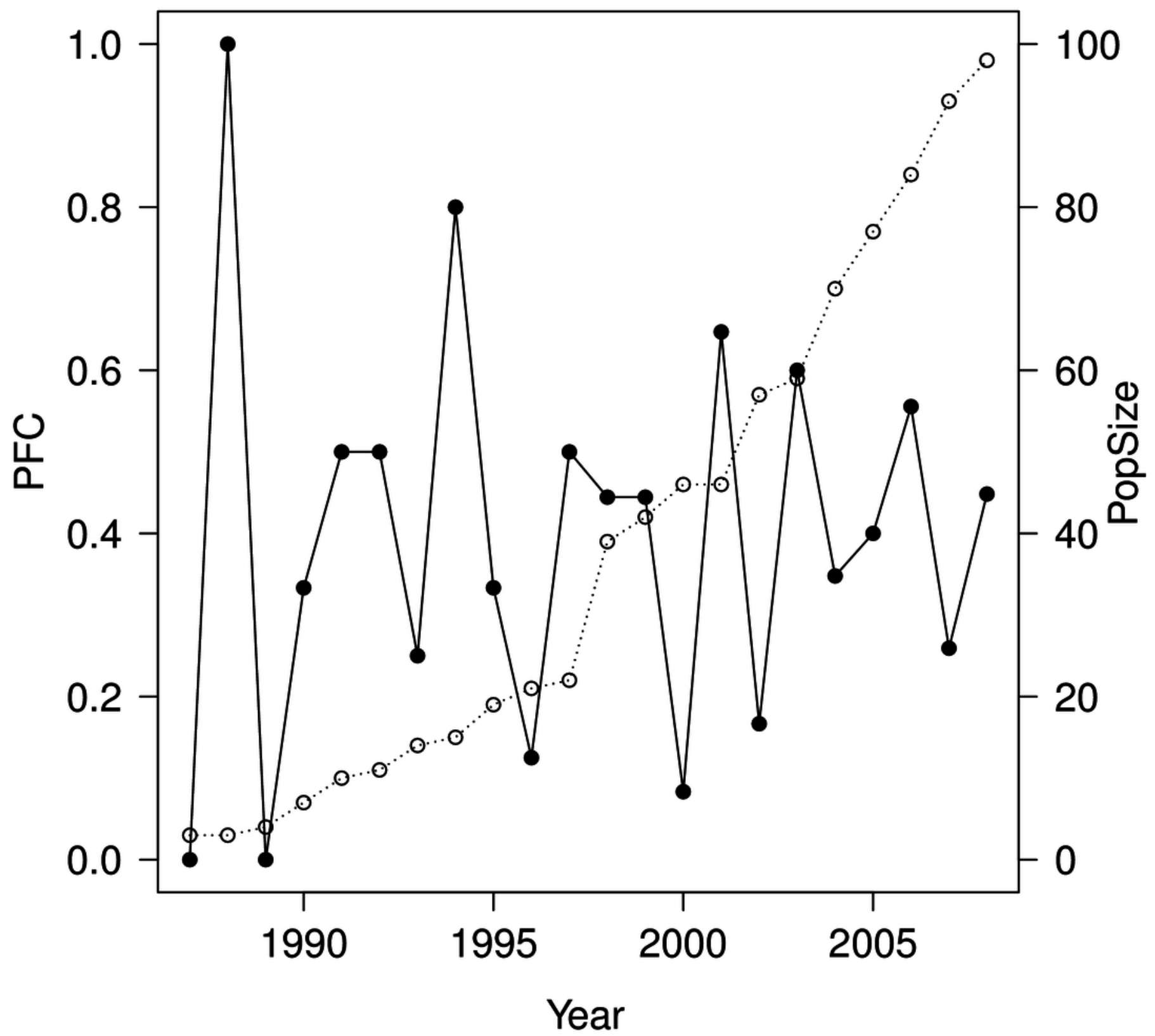


Figure 2

The raw data PFC $(\bullet)$, its arcsine-square root transform $(O)$ and the modified version of Zar (1999; equ. 13.8) transPFC( $\mathbf{\Lambda})$.

Both transformations preserve the pattern of variation in the raw data but transPFC is more faithful than the conventional arcsine transform when raw data values close to one.

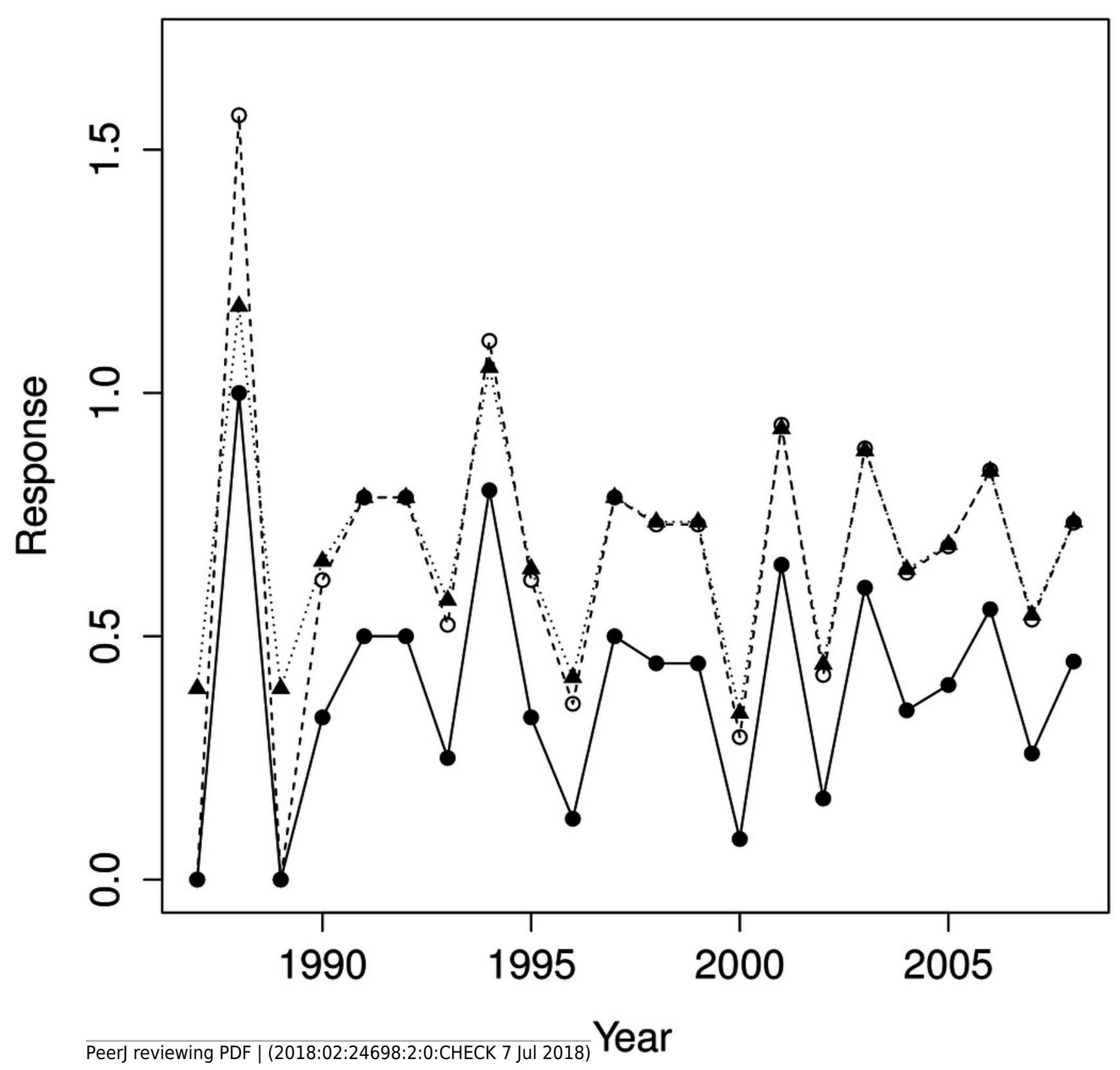




\section{Figure 3}

Autocorrelations (ACF; A) and partial autocorrelations (partialACF; B) for the time series of transformed PFC values, transPFC.

The plots were obtained using the R functions acf and $\operatorname{acf}(p)$, respectively. Horizontal dashed lines indicate $95 \%$ significance levels. Only the autocorrelation of the first lag reaches that significance level but the partial autocorrelation of the second lag only negligibly fails to do so. 
A

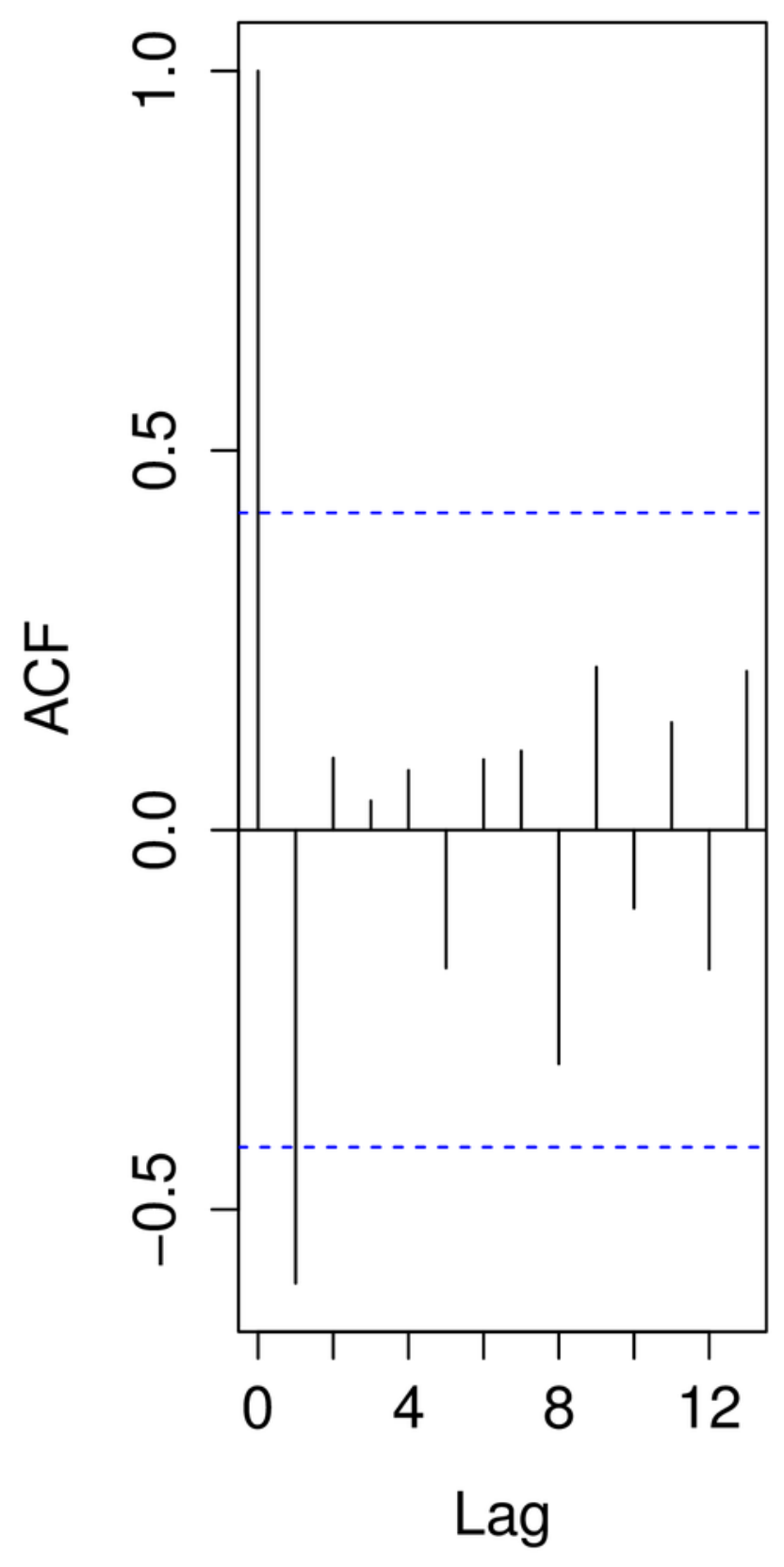

B

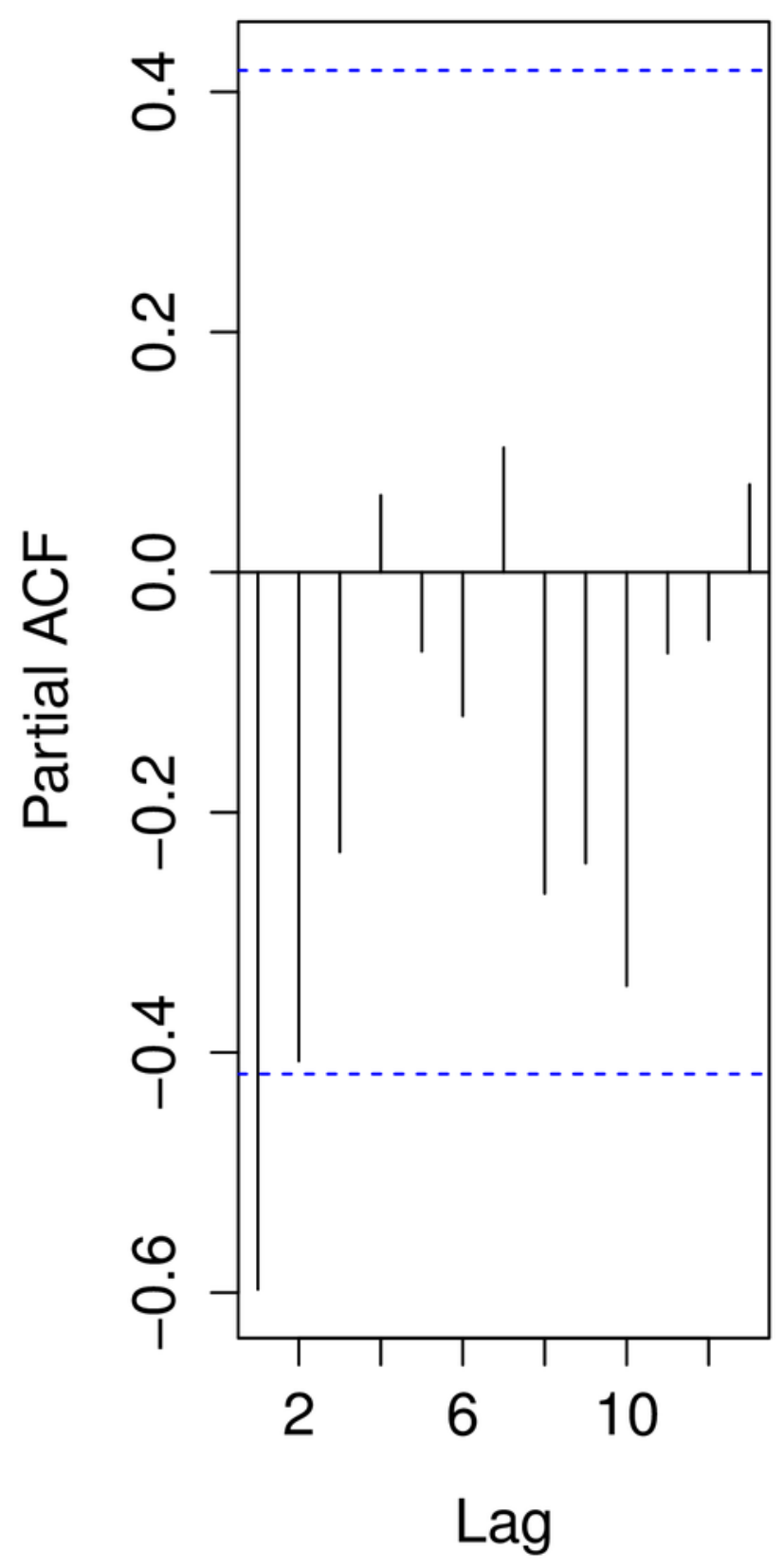


Table $\mathbf{1}$ (on next page)

Demographic history of the study population 
1 Demographic history of the study population.

2

\begin{tabular}{|c|c|c|c|c|c|c|c|}
\hline Year & PFC & $\begin{array}{l}\text { Female } \\
\text { Calves }\end{array}$ & $\begin{array}{l}\text { Female } \\
\text { Subadults }\end{array}$ & $\begin{array}{l}\text { Female } \\
\text { adults }\end{array}$ & $\begin{array}{l}\text { Male } \\
\text { calves }\end{array}$ & $\begin{array}{l}\text { Male } \\
\text { subadults }\end{array}$ & $\begin{array}{l}\text { Male } \\
\text { adults }\end{array}$ \\
\hline 1986 & na & 0 & 1 (import) & $\begin{array}{l}1 \\
\text { (import) }\end{array}$ & 0 & 0 & $\begin{array}{l}1 \\
\text { (import) }\end{array}$ \\
\hline 1987 & 0 & 0 & 1 & 1 & 0 & 0 & 1 \\
\hline 1988 & 1 & 1 & 1 & 1 & 0 & 0 & 1 \\
\hline 1989 & 0 & 1 & $\begin{array}{l}3 \text { (2 } \\
\text { imports) }\end{array}$ & 1 & 0 & $\begin{array}{l}1 \\
\text { (import) }\end{array}$ & 1 \\
\hline 1990 & 0.3333 & 2 & 2 & $\begin{array}{l}3 \text { (1 } \\
\text { import) }\end{array}$ & 0 & $\begin{array}{l}2(1 \\
\text { import) }\end{array}$ & 1 \\
\hline 1991 & 0.5 & 2 & 1 & 4 & 1 & 2 & 1 \\
\hline 1992 & 0.5 & 3 & 2 (1 import) & 4 & 2 & 2 & $\begin{array}{l}1 \\
\text { (import) }\end{array}$ \\
\hline 1993 & 0.25 & 2 & 4 & 4 & 2 & 0 & 3 \\
\hline 1994 & 0.8 & 4 & 4 & 5 & 1 & 2 & 3 \\
\hline 1995 & 0.3333 & 3 & 4 & 6 & 3 & 2 & 3 \\
\hline 1996 & 0.125 & 3 & 2 & 8 & 4 & 2 & 3 \\
\hline 1997 & 0.5 & 4 & $\begin{array}{l}12 \text { (7 } \\
\text { imports) }\end{array}$ & 8 & 2 & $\begin{array}{l}9 \text { (5 } \\
\text { imports) }\end{array}$ & $\begin{array}{l}4 \text { (1 } \\
\text { import) }\end{array}$ \\
\hline 1998 & 0.4444 & 5 & 11 & 8 & 3 & 11 & 4 \\
\hline 1999 & 0.4444 & 6 & 13 & 9 & 3 & 10 & 5 \\
\hline 2000 & 0.0833 & 7 & 9 & 12 & 3 & 9 & 6 \\
\hline 2001 & 0.6471 & 6 & 9 & 17 & 7 & 12 & 6 \\
\hline 2002 & 0.1667 & 7 & 9 & 18 & 7 & 8 & 10 \\
\hline 2003 & 0.6 & 12 & 10 & 20 & 7 & 7 & 14 \\
\hline 2004 & 0.3478 & 13 & 11 & 23 & 7 & 8 & 15 \\
\hline 2005 & 0.4 & 12 & 13 & 24 & 10 & 10 & 15 \\
\hline 2006 & 0.5556 & 12 & $\begin{array}{l}14 \text { (4 } \\
\text { exports) }\end{array}$ & 27 & 14 & $\begin{array}{l}9(1 \\
\text { export) }\end{array}$ & 17 \\
\hline 2007 & 0.2593 & 11 & 16 & 27 & 15 & 13 & 16 \\
\hline 2008 & 0.4483 & 14 & 19 & 29 & 13 & 19 & 16 \\
\hline
\end{tabular}




\section{Table 2 (on next page)}

Model rankings for $\mathrm{AR}(2)$ models for which the cumulative Akaike weights sum to 0.95

The covariates in these models are: TransPFC $_{1}$ and transPFC 2 are the one-step and two-step lags of the transformed PFC values transPFC; rain, the total rainfall for the calendar year for which PFC was computed; rain1, the total rainfall for the prior year; and density, the population density at the beginning of the year for which PFC was computed. 
1 Model rankings for $\mathrm{AR}(2)$ models for which the cumulative Akaike weights sum to 0.95 .

\begin{tabular}{|c|c|c|c|}
\hline Model & $\Delta \mathrm{AIC}_{\mathrm{c}}$ & Model & $\Delta \mathrm{AIC}_{\mathrm{c}}$ \\
\hline $\operatorname{trans} \mathrm{PFC}_{1}+\operatorname{trans} \mathrm{PFC}_{2}$ & 0 & $\operatorname{transPFC}_{1}+$ transPFC $_{2}+$ density & 3.47 \\
\hline $\operatorname{transPFC}{ }_{1}$ & 0.07 & $\operatorname{trans} \mathrm{PFC}_{1}+$ trans $\mathrm{PFC}_{2}+$ rain + rain 1 & 5.36 \\
\hline $\operatorname{trans} \mathrm{PFC}_{1}+$ trans $\mathrm{PFC}_{2}+$ rain & 1.55 & null & 5.39 \\
\hline $\operatorname{trans} \mathrm{PFC}_{1}+$ rain & 2.30 & rain & 5.47 \\
\hline $\operatorname{trans} \mathrm{PFC}_{1}+$ rain 1 & 3.14 & trans $\mathrm{PFC}_{1}+$ trans $\mathrm{PFC}_{2}+$ density + rain & 5.49 \\
\hline transPFC $1+$ density & 3.14 & $\operatorname{trans} \mathrm{PFC}_{1}+$ rain + rain 1 & 5.79 \\
\hline $\operatorname{trans} \mathrm{PFC}_{1}+\operatorname{trans} \mathrm{PFC}_{2}+$ rain 1 & 3.31 & transPFC ${ }_{1}+$ density + rain & 5.79 \\
\hline
\end{tabular}

2

3 The covariates in these models are: TransPFC $_{1}$ and transPFC $\mathrm{P}_{2}$ are the one-step and two-step lags 4 of the transformed PFC values transPFC; rain, the total rainfall for the calendar year for which 5 PFC was computed; rain1, the total rainfall for the prior year; and density, the population 6 density at the beginning of the year for which PFC was computed. 